\title{
Double blind placebo controlled crossover clinical trial of sildenafil citrate in patients with diabetes mellitus and erectile dysfunction
}

\author{
A Keshani Warusawithana ${ }^{1}$, A D A Fernando², K Guruparan ${ }^{3}$, T J Athukorala ${ }^{3}$, Colvin Goonaratna
}

Journal of the Ceylon College of Physicians, 2010, 41, 72-75

(Peer reviewed)

\begin{abstract}
Objective: To assess the efficacy, side-effects and client acceptability of oral sildenafil citrate in patients with diabetes mellitus having erectile dysfunction
\end{abstract}

Method: 103 diabetes patients with erectile dysfunction attending the Endocrine Clinic at National Hospital of Sri Lanka were selected for the study. Sildenafil citrate $50 \mathrm{mg}$ or placebo was given to alternate patients, and after a wash-out period of 2 weeks, those who received the drug were given the placebo and vice versa. The 5item version of International Index of Erectile Function (IIEF-5) was used to assess the degree of erectile dysfunction. IIEF-5 was assessed before and after the placebo and the drug.

Results: 95 (92.3\%) patients completed the study. There was a significant improvement $(P<0.001)$ in IIEF-5 score after sildenafil citrate (IIEF-5 mean 17.1) when compared to placebo (IIEF-5 mean 10.7). 48 (50.5\%) patients had at least one side-effect attributable to the drug. These were transient and mild in nature, and included transient nasal congestion, gastrointestinal disturbances, disturbance of colour vision, headache, dizziness and faintness. 92 (96.8\%) patients said that the use of sildenafil citrate was acceptable to them and their partners.

Conclusion: Sildenafil citrate is an effective drug in the management of erectile dysfunction in patients having diabetes mellitus, with only transient and mild side-effects. Acceptability of the drug by patients and their partners was very high. Males with diabetes expect their physicians to initiate a dialogue on their sexual functioning.

\footnotetext{
${ }^{1}$ Lecturer,

2 Senior Lecturer,

${ }^{3}$ Demonstrator,

${ }^{4}$ Emeritus Professor, Department of Physiology, Faculty of Medicine, University of Colombo.
}

\section{Introduction}

Erectile dysfunction (ED), the persistent inability to achieve or maintain an erection sufficient for satisfactory sexual performance ${ }^{1}$, is a common problem in patients with diabetes mellitus (DM) ${ }^{2,3}$. In Sri Lanka ED is under-diagnosed, as many patients do not divulge this problem and doctors are reluctant to probe this because of personal, environmental and cultural factors.

Sildenafil citrate is an effective drug for the management of $E D^{4,5,6}$. It is a potent and selective phosphodiesterase type 5 inhibitor. It restores erection only with sexual stimulation. The effectiveness of sildenafil citrate for ED in patients having DM varies from $59 \%$ to $63 \%$ in western studies ${ }^{2,6}$. There are no double blind, placebo controlled clinical trials on sildenafil citrate for patients with DM having ED in Sri Lanka or in southeast Asia.

We designed this clinical trial to assess the efficacy, side-effects and the acceptability of sildenafil citrate for the treatment of ED among diabetes patients in a Sri Lankan cohort.

\section{Method}

103 patients with ED attending the Endocrine Clinic at the National Hospital of Sri Lanka (NHSL) were selected after excluding patients taking nitrates, which is an absolute contraindication for sildenafil citrate therapy, and those who had a history of myocardial infarction, unstable angina, stroke or hypotension. Patients were between 34 to 73 years old, and the duration of DM ranged from 3 to 360 months (Table 1).

Patients were given verbal and written information regarding the nature and objectives of the trial and verbal informed consent was obtained. They were allowed the option of withdrawing from the trial at any time. Approval for the study was granted by the Sri Lanka Medical Association's Ethical Review Committee.

Data were collected using an interviewer administered questionnaire and a self-administered IIEF-5 questionnaire ${ }^{7,8}$. The IIEF-5 is an internationally validated questionnaire designed for the assessment of male erectile function. The English version was 
translated into Tamil and Sinhala, and back translated by language specialists. All 3 versions were checked for cultural appropriateness by focus groups. It has 5 questions to address different aspects of erectile function, and the score ranges from 5 to 25 . A score of less than 21 is considered as $\mathrm{ED}^{7}$.

Three tablets of either sildenafil citrate $\left(\right.$ Cupid $\left.^{\circledR}\right)$ $50 \mathrm{mg}$ or placebo were given to alternate patients with verbal and written instructions regarding the use of the drug. After a washout period of 2 weeks patients who were initially given the drug were given the placebo, and vice versa. IIEF- 5 was assessed before treatment, after the drug and after the placebo. Patients were informed about the common adverse effects ${ }^{4,5}$ of the treatment and asked to report if they experienced any. Patients and assessors of outcome were blind to the treatment.

\section{Results}

Out of 103 patients recruited, 95 (92.3\%) completed the study. Mean value of IIEF- 5 before treatment was 10.5 (SD 4.5) and after treatment with sildenafil citrate it had risen up to 17.1 (SD 4.5). Mean value of
IIEF-5 after placebo was 10.7 (SD 4.1). When paired sample T test was applied, the increase in IIEF-5 with the use of sildenafil citrate was statistically significant $(P<0.001)$, but the increase in IIEF-5 after taking placebo was not significant $(P=0.547)$. With sildenafil citrate the improvement in all five aspects of IIEF-5 was significant when analysed separately, but the change was not significant in any of the 5 aspects of IIEF with the placebo (Table 2). Table 3 shows the change in IIEF-5 score before and after treatment with sildenafil citrate and placebo. 8 (7.7\%) patients did not complete the study. Of the patients who did not report for the second drug 4 had received sildenafil citrate and 4 had received the placebo.

Forty eight $(50.5 \%)$ patients reported at least a single side-effect attributable to the drug but none of the patients discontinued treatment due to sideeffects. For placebo only 7 (7.4\%) patients reported side-effects (Table 4).

92 (96.8\%) patients said that the use of drug for ED was acceptable to them as well as their partners, and the way this sensitive issue was handled by the research team was acceptable to them.

Table 1. Age distribution and duration of DM $(n=95)$

\begin{tabular}{lll}
\hline Age distribution & Age group (Years) & Number \\
\hline & $31-40$ & 9 \\
$41-50$ & 18 \\
Duration of diabetes mellitus & $51-60$ & 39 \\
& $61-70$ & 26 \\
& $>70$ & 3 \\
& Months & Number \\
\hline $3-24$ & 13 \\
$25-48$ & 11 \\
$49-72$ & 21 \\
$73-96$ & 10 \\
$97-120$ & $121-144$ \\
\hline
\end{tabular}


Table 2. Comparison of mean values of IIEF-5 before and after treatment with sildenafil citrate and placebo $(n=95)$

\begin{tabular}{|c|c|c|c|c|c|}
\hline Question & $\begin{array}{l}\text { Before } \\
\text { treatment }\end{array}$ & $\begin{array}{l}\text { After } \\
\text { sildenafil } \\
\text { citrate }\end{array}$ & $\begin{array}{l}P \text { value } \\
\text { after } \\
\text { sildenafil }\end{array}$ & $\begin{array}{l}\text { After } \\
\text { placebo }\end{array}$ & $\begin{array}{l}P \text { value } \\
\text { after } \\
\text { placebo }\end{array}$ \\
\hline $\begin{array}{l}\text { 1. How do you rate your } \\
\text { confidence that you could get } \\
\text { and keep an erection? }\end{array}$ & 2.1 & 3.3 & $<0.001$ & 2.2 & 0.27 \\
\hline $\begin{array}{l}\text { 2. When you had erections } \\
\text { with sexual stimulation, how } \\
\text { often were your erections } \\
\text { hard enough for penetration? }\end{array}$ & 2.1 & 3.4 & $<0.001$ & 2.1 & 0.72 \\
\hline $\begin{array}{l}\text { 3. During sexual intercourse, } \\
\text { how often were you able to } \\
\text { maintain your erection after } \\
\text { you had penetrated your } \\
\text { partner? }\end{array}$ & 2.0 & 3.5 & $<0.001$ & 2.1 & 0.25 \\
\hline $\begin{array}{l}\text { 4. During sexual intercourse } \\
\text { how often were you able to } \\
\text { maintain the erection to } \\
\text { semen ejaculation? }\end{array}$ & 2.2 & 3.5 & $<0.001$ & 2.2 & 0.72 \\
\hline $\begin{array}{l}\text { 5. When you attempted sexual } \\
\text { intercourse, how often was it } \\
\text { satisfactory for you? }\end{array}$ & 2.1 & 3.5 & $<0.001$ & 2.0 & 0.73 \\
\hline Total score of IIEF-5 & 10.5 & 17.1 & $<0.001$ & 10.7 & 0.58 \\
\hline
\end{tabular}

Table 3. Change in IIEF-5 score after treatment with sildenafil citrate and with placebo $(n=95)$

\begin{tabular}{|c|c|c|c|c|c|c|c|c|c|}
\hline \multirow[t]{2}{*}{$\begin{array}{l}\text { IIEF-5 score } \\
\text { before treatment }\end{array}$} & \multirow[t]{2}{*}{$n$} & \multicolumn{4}{|c|}{$\begin{array}{c}\text { Achievement of IIEF-5 score } \\
\text { after sildenafil citrate }\end{array}$} & \multicolumn{4}{|c|}{$\begin{array}{c}\text { Achievement of IIEF-5 score } \\
\text { after placebo }\end{array}$} \\
\hline & & $\begin{array}{c}\geq 21 \\
n\end{array}$ & $\begin{array}{c}20-16 \\
n\end{array}$ & $\begin{array}{c}15-11 \\
n\end{array}$ & $\begin{array}{c}\leq 10 \\
n\end{array}$ & $\begin{array}{c}\geq 21 \\
n\end{array}$ & $\begin{array}{c}20-16 \\
n\end{array}$ & $\begin{array}{c}15-11 \\
n\end{array}$ & $\begin{array}{c}\leq 10 \\
n\end{array}$ \\
\hline $20-16$ & 14 & 7 & 5 & 2 & 0 & 1 & 7 & 3 & 3 \\
\hline $15-11$ & 29 & 4 & 12 & 13 & 0 & 0 & 1 & 17 & 11 \\
\hline$\leq 10$ & 52 & 7 & 19 & 19 & 7 & 0 & 4 & 11 & 37 \\
\hline Total & 95 & 18 & 36 & 34 & 7 & 1 & 12 & 31 & 51 \\
\hline
\end{tabular}


Table 4. Side-effects reported by patients $(n=95)$

\begin{tabular}{|c|c|c|}
\hline Side-effect & Sildenafil citrate (\%) & Placebo (\%) \\
\hline Nasal congestion & $33(34.7 \%)$ & $4(4.2 \%)$ \\
\hline Gastrointestinal disturbances & $27(28.4 \%)$ & $1(1.1 \%)$ \\
\hline Visual disturbances & $10(10.5 \%)$ & $1(1.1 \%)$ \\
\hline Headache & $7 \quad(7.4 \%)$ & $1(1.1 \%)$ \\
\hline Dizziness and faintness & 3 (3.1\%) & $2(2.1 \%)$ \\
\hline Priapism & Nil & Nil \\
\hline
\end{tabular}

\section{Discussion}

Our study showed that sildenafil citrate is an effective treatment for diabetes patients who have ED in Sri Lanka.

$50.5 \%$ patients reported some side-effects, but they were transient and mild in nature.

Informal discussions with specialist and nonspecialist colleagues suggest that the problem of ED is inadequately addressed by practitioners in Sri Lanka due to a number of reasons including lack of privacy in crowded clinic settings, lack of appropriate communication skills and cultural factors.

However, in our study there was $96.8 \%$ acceptability by the patients showing that they appreciated the intervention and expected doctors to manage the problem of ED appropriately. Clearly clinicians have a responsibility to identify and prescribe appropriate treatment to correct this distressing condition.

\section{Acknowledgements}

We thank Dr N Somasundaram, consultant endocrinologist, NHSL for granting permission to conduct the clinical trial at the Endocrine Clinic of NHSL, Professor L Rajapakse for helping us with the statistics, Lanka Medical Imports Ltd for donating
Cupid $^{\circledR}$ and State Pharmaceutical Manufacturing Corporation (SPMC) for providing the placebo and Cupid .

\section{References}

1. Impotence. NIH Consensus Statement. 1992 Dec 7-9; 10: 1-33.

2. Kumar P, Clark M. Clinical Medicine: Complications of Diabetes, 2005; 6: 1120-30.

3. S Ginige.Global burden of diabetes, 1995 - 2025 Weekly Epidemiological Report Ministry of Healthcare and Nutrition Sri Lanka 2006; 33 No 15: 1-2.

4. Goldstein I, Lue TF, Padmanathan H, Rosen R C, Steers WD, et al. Oral sildenafil in the treatment of erectile dysfunction. New England Journal of Medicine 1998; 338: 1397-404.

5. British National Formulary 2006; 52: 433.

6. J Dey, M D Shepherd. Evaluation and treatment of erectile dysfunction in men with diabetes mellitus. Mayo Clinic Proceedings 2002; 77: 276-82.

7. E L Rhoden, C Telöken, P R Sogari, C A Vargas Souto. The use of the simplified International Index of Erectile Function (IIEF-5) as a diagnostic tool to study the prevalence of erectile dysfunction. International Journal of Impotence Research 2002; 14: 245-50.

8. J K Tan, C Y Hong, D J C Png, L C H Liew, M L Wong. Erectile dysfunction in Singapore: Prevalence and its associated factors - a population based study. Singapore Medical Journal 2003; 44: 20-6. 